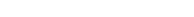

ISSN 1991-8631

Original Paper

http://indexmedicus.afro.who.int

\title{
Levels of pesticide residues in irrigation effluent from tomato fields in Owiro Estate, Tanzania
}

\author{
Charles KIHAMPA $^{1 *}$, Rubhera RAM MATO ${ }^{1}$ and Hussein MOHAMED ${ }^{2}$ \\ ${ }^{1}$ School of Environmental Science and Technology, Ardhi University, P.O. Box 35176 \\ Dar es Salaam, Tanzania. \\ ${ }^{2}$ Department of Environmental and Occupational Health, Muhimbili University of Health and Allied Sciences, \\ P. O. Box 65015, Dar es Salaam, Tanzania. \\ *Corresponding author, E-mail: kihampa@yahoo.com; Tel. +255-22-2771272; Fax +255-22-2775448
}

\begin{abstract}
Pesticide residues lindane, chlorpyrifos and endosulfan sulphate were detected in water from the spring source, within field and return channel of vegetable farms in Ngarenanyuki, Tanzania. Extraction of the pesticide residues were conducted by liquid-liquid extraction (LLE) method. The detection and concentrations of pesticide residues were determined by gas chromatography equipped with electron capture detector (GCECD). The percentage detections in return channel and within field were observed to be 67 and 33 respectively whereas no pesticides were detected in the spring source. The average concentrations for lindane, chlorpyrifos and endosulfan sulphate within field and return channel were 3.0, 0.27 and 3.35, and 2.8, 0.06 and 3.13 mg/L, respectively. Absence of residues detection in spring source indicates that the source of pesticides in water from the field and return channel were the applications of pesticides in vegetable farms. This work, thus, seeks to provide information on levels of pesticide residues in water that will assist in a scientific assessment of the impact of pesticides application on public health and ecosystem in Tanzania.

(C) 2010 International Formulae Group. All rights reserved.
\end{abstract}

Keywords: Organochlorines, Organophosphorous, Water contamination, Ngarenanyuki.

\section{INTRODUCTION}

Environmental contamination of natural waters by pesticide residues is of great concern these days (Kolpin et al., 2004). Water pollution by pesticides can affect many biological systems, it may take very long time to clear and pose danger of bioaccumulation (Dalvie et al., 2003). For example organochlorine pesticides are known to resist biodegradation, can be recycled through food chains and produce a significant magnification of the original concentration at the end of the chain (Dem et al., 2007).
The widespread use of synthetic pesticides over the past half-century has led to their detection in many hydrologic systems of many countries (Kolpin, 2000). Despite the fact that pesticides are also applied in other sectors, agriculture is undoubtedly seen as the most important source of this contamination. Pesticide residues from agriculture areas can reach the aquatic environment through direct run off, leaching, careless disposal of empty containers, equipment washings, etc. (Sattler et al., 2007). The growing awareness of the risks related to the intensive use of pesticides 
has led to a more critical attitude by the society towards agriculture. There is also a change in consumer concerns that had put more weight on issues such as environmental friendliness in agricultural production and food safety (Saba and Messina, 2003). Several studies on pesticide residues from agriculture effluent have been conducted in other parts of the world, but very few investigations have assessed the pesticide residues in water bodies from irrigation effluent of Tanzania. The objective of this work was to ascertain the level of pesticide residues in surface water from the irrigated vegetable farms in Ngarenanyuki, Tanzania.

\section{MATERIALS AND METHODS}

\section{Study area and sample collection}

Ngarenanyuki is among the 17 wards in Arumeru District, Arusha City, Tanzania. It comprises of five villages (Uwiro, Ngabobo, Olkung'wado, Kisimiri chini and Kisimiri juu) located at the foot of Mt. Meru (Figure 1 ), north east of Arusha City ( $3^{\circ} 9^{\prime} 0^{\prime \prime}$ South, $36^{\circ} 51^{\prime} 0^{\prime \prime}$ East). The study was conducted at Uwiro Estate in January and February 2009. Interview, questionnaire, observations and site photos were used to obtain information from farmers, agriculture officers and shopkeepers. During the study visits, water used for irrigation was found to come from River Ngarenanyuki and natural springs namely Bulebule that passes through Mama Lesi farms. Water from Bulebule spring is conveyed to farms by open channels, passes through the field and goes back to main channel and ends up in villages located far away from Ngarenanyuki area.

A total of 15 water samples were collected from Uwiro Estates (Figure 1; W1W15) using one litre sampling bottles with Teflon stop cork. Sampling points were selected and located by Geographical Positioning System (GPS) instrument. The samples were collected from three locations, which were main channel at the spring water source, channels within the field, and return channel after water has been used for irrigation. Before sampling, the bottles were washed with detergents, rinsed with tap water and distilled water, and finally with acetone, followed by oven drying at $170{ }^{\circ} \mathrm{C}$ for $2 \mathrm{~h}$. Before samples were collected, the glass bottles were rinsed twice with the water samples then carefully filled just to overflowing, without passing air bubbles through the samples or trapping air bubbles in sealed bottles. Samples were then acidified to $\mathrm{pH} 2.5$ with hydrochloric acid to inhibit biological activity and were filled through fibre glass filters to remove sand and debris. After sampling, the bottles were carried to Ardhi University, Laboratory of School of Environmental Science and Technology and stored in the dark at temperatures between 0 and $4{ }^{\circ} \mathrm{C}$ prior to extraction.

\section{Chemicals}

Chromatography grade dichloromethane, n-hexane, acetone, cyclohexane and ethyl acetate were used for sample preparation. Samples were quantified using pesticide standard mixture which had over $99 \%$ certified purity. Laboratory glassware were washed with detergents, rinsed with distilled water and acetone, and then dried in an oven at $110{ }^{\circ} \mathrm{C}$ overnight prior to use.

\section{Extraction and clean up}

Unfiltered water samples, previously preserved with $10 \% \mathrm{NaCl}$, were extracted by Liquid-Liquid Extraction (LLE) method (Åkerblom, 1995). Each water sample (1000 $\mathrm{ml}$ ) was quantitatively transferred to a $1 \mathrm{~L}$ separating funnel and the sampling bottle was rinsed with dichloromethane $(30 \mathrm{~mL})$ which was then combined with the water sample in the separating funnel. The combined contents were then successively extracted with dichloromethane $(3 \times 50 \mathrm{~mL})$. The organic layer was filtered through plug wool containing anhydrous sodium sulphate (30 g) for drying. Sodium sulphate was later rinsed with dichloromethane $(2 \times 3 \mathrm{~mL})$ and the combined extract concentrated in vacuo at 30 ${ }^{\circ} \mathrm{C}$ and the solvent changed to cyclohexane. The volume was adjusted in a stream of air to 
$2 \mathrm{ml}$ in 9:1 cyclohexane:acetone (v/v) in vials ready for analysis. The water extract appeared clean and were not subjected to further clean up.

\section{Analytical quality assurance}

A $100 \mathrm{~mL}$ aliquot of each $\mathrm{n}$-hexane, dichloromethane, cyclohexane, ethyl acetate and acetone was concentrated to $2 \mathrm{~mL}$ and used to check the contamination from the solvents used. A blank water sample of $1 \mathrm{~L}$ of distilled water was extracted the same way as water samples. No pesticides were detected in the blanks. Recoveries were estimated by spiking the matrix blank with 4 organochlorine pesticides and one organophosphorous pesticide standards at concentrations ranging from 0.01 to 1.1 $\mu \mathrm{g} / \mathrm{mL}$ of each analyte. The average ( \pm SD) percentage recoveries were as follows: Lindane $95.7 \pm 0.7 \%$, Chlorpyrifos $81.2 \pm 3.6$ $\%, p^{\prime}, p$ - DDE $94.5 \pm 1 \%$, and $p^{\prime}, p$-DDD $97.7 \pm 0.7 \%(n=4)$. The results were not corrected for recoveries since they were observed to lie within the normal acceptable range of 70-120\% (Hill, 2000).

\section{Sample analysis}

Analysis of the pesticide residues was done as described by Åkerblom (1995). GCVarian CP-3800 gas chromatography equipped with ${ }^{63} \mathrm{Ni}$ Electron Capture (EC) detector was used for analysis. The GC capillary column WCOT FUSED SILICA 30 $\mathrm{m} \times 0.32 \mathrm{~mm}$, coated with CP-SIL 8CB DF $1.0 \mu \mathrm{m}$ was used. Nitrogen was used as both a carrier and make up gas in the Electron Capture Detector (ECD) at a flow rate of $30 \pm$ $1 \mathrm{~mL} / \mathrm{min}$. The GC column temperature program was $70{ }^{\circ} \mathrm{C}$ for $1 \mathrm{~min}$ followed by 15 ${ }^{\circ} \mathrm{C} / \mathrm{min}$ to $180{ }^{\circ} \mathrm{C}$ and $4{ }^{\circ} \mathrm{C} / \mathrm{min}$ to $230{ }^{\circ} \mathrm{C}$ held for $15 \mathrm{~min}$. The injector and detector temperatures were $240{ }^{\circ} \mathrm{C}$ and $250{ }^{\circ} \mathrm{C}$, respectively. Identification of residues was effected by running samples and external reference standards in GC and then comparing the chromatograms (Martens et al., 1999).

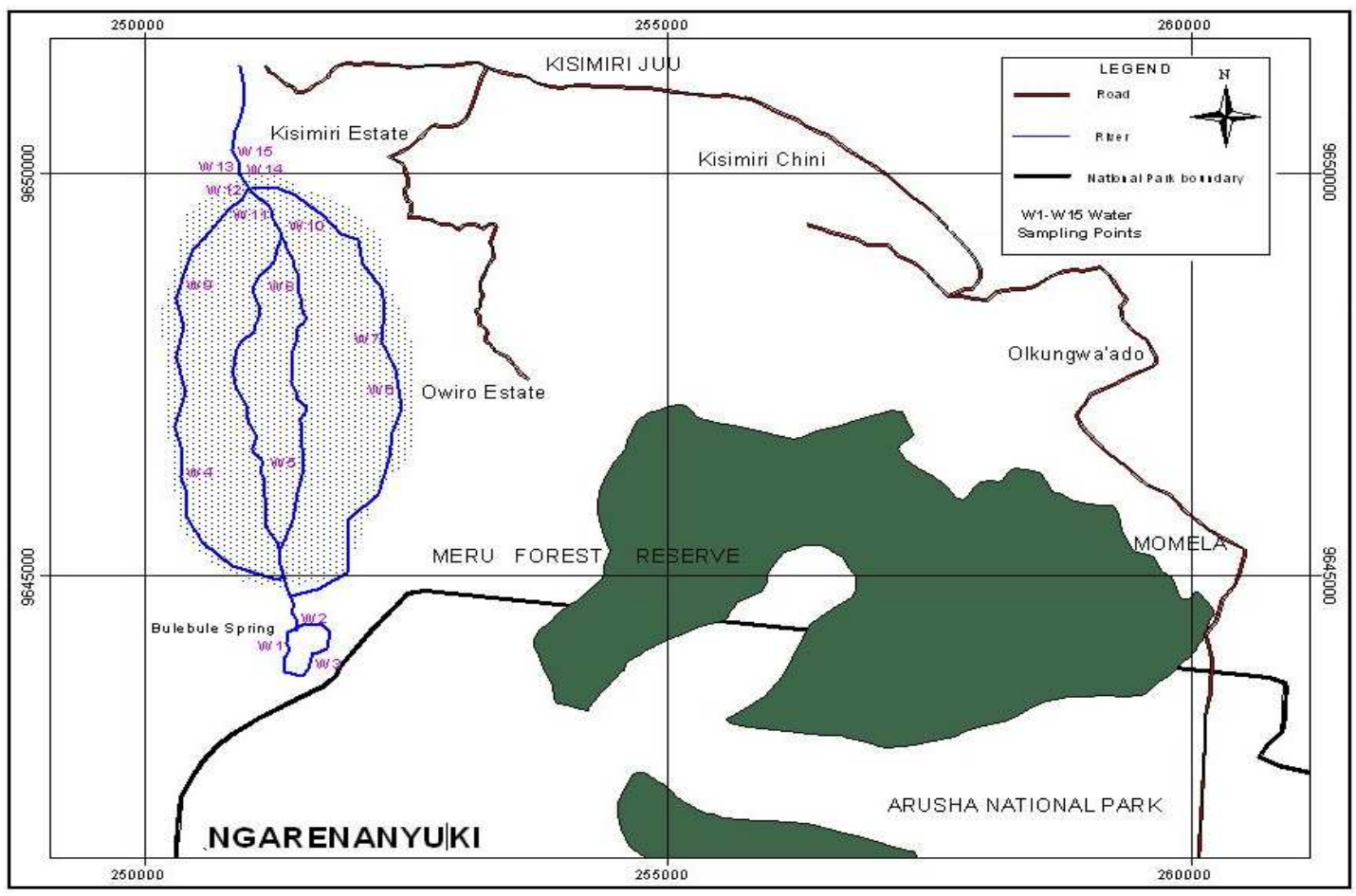

Figure 1: Map of Ngarenanyuki showing sampling sites at Uwiro. 


\section{RESULTS AND DISCUSSION}

Results of water analysis (Table 1) show varying concentrations of lindane, chlorpyrifos and endosulfan sulphate pesticide residues detected. Pesticides analysed were observed to be below the detection limits (bdl) in all the water samples collected from the source. Samples collected within the fields and in the return channel were observed to contain lindane, chlorpyrifos and endosulfan sulphate ranging from bdl to $4.0 \mathrm{mg} / \mathrm{L}$. These pesticide residues have likely originated from the farm fields due to application of pesticides. $p, p^{\prime}$-DDE and $p, p^{\prime}$-DDD were neither detected in water samples collected

Table 1: Pesticide residue concentrations $(\mathrm{mg} / \mathrm{L})$ in water.

\begin{tabular}{|c|c|c|c|c|c|c|c|}
\hline \multirow{2}{*}{$\begin{array}{l}\text { Sampling } \\
\text { location }\end{array}$} & \multicolumn{2}{|c|}{ Sampling point } & \multicolumn{5}{|c|}{ Pesticides residues $(\mathrm{mg} / \mathrm{L})$} \\
\hline & & & $\begin{array}{c}\text { Lindan } \\
\mathrm{e}\end{array}$ & $p, p^{\prime}$-DDE & $\begin{array}{l}p, p^{\prime}- \\
\text { DDD }\end{array}$ & $\begin{array}{c}\text { Chlorpyrifo } \\
\text { s }\end{array}$ & $\begin{array}{c}\text { Endosulfan } \\
\text { sulphate }\end{array}$ \\
\hline \multirow{6}{*}{$\begin{array}{l}\text { Water } \\
\text { Source }\end{array}$} & $\mathrm{W} 1$ & S 0309441 & bdl & bdl & bdl & bdl & bdl \\
\hline & & E 3651819 & & & & & \\
\hline & W2 & S 0309487 & bdl & bdl & bdl & bdl & bdl \\
\hline & & E 3651854 & & & & & \\
\hline & W3 & S 0309760 & bdl & bdl & bdl & bdl & bdl \\
\hline & & E 3651902 & & & & & \\
\hline \multirow[t]{3}{*}{ Average } & & - & & - & - & - & - \\
\hline & W4 & S 0309321 & 2.0 & bdl & bdl & 0.04 & 3.7 \\
\hline & & Е 3651469 & & & & & \\
\hline \multirow{10}{*}{$\begin{array}{l}\text { Within the } \\
\text { field }\end{array}$} & W5 & S 0309812 & bdl & bdl & bdl & bdl & bdl \\
\hline & & E 3651902 & & & & & \\
\hline & W6 & S 0309811 & bdl & bdl & bdl & bdl & bdl \\
\hline & & Е 3651633 & & & & & \\
\hline & W7 & S 0309230 & bdl & bdl & bdl & bdl & bdl \\
\hline & & E 3651522 & & & & & \\
\hline & W8 & S 0309319 & 4.0 & bdl & bdl & 0.5 & 3.0 \\
\hline & & E 3651105 & & & & & \\
\hline & W9 & S 0309934 & bdl & bdl & bdl & bdl & bdl \\
\hline & & E 3651522 & & & & & \\
\hline \multirow[t]{3}{*}{ Average } & & & 3.0 & - & - & 0.27 & 3.35 \\
\hline & W10 & S 0309672 & bdl & bdl & bdl & bdl & bdl \\
\hline & & Е 3651196 & & & & & \\
\hline \multirow{10}{*}{$\begin{array}{l}\text { Return } \\
\text { channel }\end{array}$} & W11 & S 0309766 & bdl & bdl & bdl & bdl & bdl \\
\hline & & Е 3651765 & & & & & \\
\hline & W12 & S 0309188 & 3.2 & bdl & bdl & 0.05 & 4.0 \\
\hline & & E 3651833 & & & & & \\
\hline & W13 & S 0309677 & 3.0 & bdl & bdl & 0.07 & 3.0 \\
\hline & & E 3651117 & & & & & \\
\hline & W14 & S 0309915 & 2.6 & bdl & bdl & 0.04 & 2.8 \\
\hline & & Е 3651976 & & & & & \\
\hline & W15 & S 0309433 & 2.3 & bdl & bdl & 0.06 & 2.7 \\
\hline & & Е 3651745 & & & & & \\
\hline Average & & & 2.8 & - & - & 0.06 & 3.13 \\
\hline
\end{tabular}


within the fields nor in return channels. This can be due to the fact that the use of DDT pesticide in Ngarenanyuki was discontinued more than ten years ago, as a result of the international conventions that aim to protect human health and the environment by requiring parties to take measures to reduce or eliminate releases of persistent organic pollutants (POPs) from intentional production and use, stockpiles and wastes, and unintentional release (Karstensen et al., 2006). Another reason is its extremely low solubility in water of $0.003 \mathrm{mg} / \mathrm{L}$ (Mackay et al., 1997) and as such it is normally highly retained by soils with high organic matter content (WHO, 1989).

Lindane was detected in $40 \%$ of the water samples analysed with an average concentration of $2.8 \mathrm{mg} / \mathrm{L}$. This rate is less than that reported by Manirakiza et al. (2003), where $90 \%$ lindane was detected in all samples collected from West African City farms (Banjul and Dakar). There are several mechanisms that can be the cause of observed differences including soil type, microbial degradation, chemical hydrolysis, photolysis, sorption, leaching and plant uptake. The percentage detection within the field and in the return channel was 33 and $67 \%$ with an average concentration of 3.0 and $2.8 \mathrm{mg} / \mathrm{L}$, respectively. Higher concentrations in the return channel are due the fact that the channel collects water from all channels traversing the fields. However, the high average concentration within the fields shows that it is highly concentrated within the fields which is the point source for the occurrence detected in return channel. The occurrence of lindane, which is not currently used as explained by farmers, indicates past usage of this persistent organic pesticide (Manirakiza et al., 2003).

Endosulfan sulphate was detected in 6 (40\%) out of 15 water samples analysed and the average concentration was $3.2 \mathrm{mg} / \mathrm{L}$. The pesticide was detected in $2(33 \%)$ out of 6 water samples collected within the field with an average concentration of $3.35 \mathrm{mg} / \mathrm{L}$, whereas in the return channel the rate of detection was $66.7 \%$ with an average concentration of $3.13 \mathrm{mg} / \mathrm{L}$. Similar observations were made in a study conducted in Egypt where endosulfan sulphate and other organochlorines were also detected in water channels (El-Kabbany et al., 2000). This shows that endosulfan sulphate is also still used in other African countries.

Chlorpyrifos was detected in 6 out of 15 water samples (40\%) analysed and the average concentration was $0.13 \mathrm{mg} / \mathrm{L}$. It was detected in 2 out of 6 water samples (33\%) collected within the field with average concentration of $0.27 \mathrm{mg} / \mathrm{L}$. The contaminant was also detected in $67.7 \%$ of the water samples collected from the return channel with average of $0.06 \mathrm{mg} / \mathrm{L}$. The presence of chlorpyrifos may imply that the pesticide was recently used since $80 \%$ of the farmers in Ngarenanyuki were observed to use chlorpyrifos under the trade name Dursban. These findings are similar to those observed in a study conducted in Malaysia where chlorpyrifos was detected in water traversing a farmland (Leong, 2007).

\section{Conclusion}

Generally, levels of pesticides residues varied depending on the origin of the sample. No pesticide residues were detected from the spring water source, frequency of detection of pesticides increased for samples collected downstream in the field. This indicates that the contamination emanated from the pesticide applications within the farms. The results from the study show that residues of pesticides are present at concentrations lower than their maximum permissible residue levels. However, if such levels will not be controlled, continued pesticides application may lead to heavy contamination of vegetables (especially tomato in this case). Such contamination poses a great health risks 
to consumers through bioaccumulation to higher levels in human beings who consume this product, thus resulting into adverse health problems. It is therefore recommended that further research should be conducted to determine the amount of pesticide residues in tomatoes, sediments and soil used for cultivation. It is also essential to put up mechanisms for monitoring of residues levels in the ecosystem as well as the food chain. The results will help in a scientific assessment of the implications of pesticide application with regards to human risks in Tanzania.

\section{ACKNOWLEDGEMENTS}

We are gratefully acknowledging the inputs of Mr. Lutufyo Mwamtobe from the Department of Chemistry, University of Dar es Salaam, and Mr. Addo Ndimbo and Ramadhani Mbulume from the School of Environmental Science and Technology, Ardhi University for their invaluable technical assistance during the laboratory extraction and analysis.

\section{REFERENCES}

Åkerblom M. 1995. Guidelines for environmental monitoring of pesticide residues for the SADC Region. SADC/ELMS, Monitoring Techniques Series 3, Lesotho.

Dalvie AM, Cairncross E, Solomon A, London L. 2003. Contamination of rural surface and ground water by endosulfan in farming areas of the Western Cape, South Africa. Environ. Health: A Global Access Sci. Source, 2: 1-15.

Dem SB, Cobb JM, Mullins DE, 2007. Pesticide residues in soil and water from four cotton growing areas of Mali, West Africa. J. Food Environ. Sci., 1: 1-12.

El-Kabbany S, Rahed MM, Zayed MA. 2000. Monitoring of pesticide levels in some water supplies and agricultural land in ElHaram, Giza (A.R.E). J. Haz. Mater., 72: 11-21.
Hill A. 2000. Quality Control Procedures for Pesticide Residues Guidelines for Residues Monitoring in the European Union (2nd edn). Document no. SANCO/3103/2000, European Commission.

Karstensen KH, Kinh NK, Thang LB, Viet PH, Tuan ND, Toi DT, Hung NH, Quan TM, Hanh LD, Thang DH. 2006. Environmentally sound destruction of obsolete pesticides in developing countries using cement kilns. Environ. Sci. Policy, 9: 577-586.

Kolpin DK, Schnoebelen DJ, Thurman EM. 2004. Degradates provide insight to spatial and temporal trends of herbicides in ground water. Ground Water, 42: 601608.

Kolpin DW, 2000. Importance of the Mississippi River Basin for investigating agricultural-chemical contamination of the hydrologic cycle: The Sci. Total Environ., 248 (2-3): 71-72.

Leong HK, Tan BLL, Mustafa MA. 2007. Contamination levels of selected organochlorine and organophosphate pesticides in the Selangor River, Malaysia between 2002 and 2003. Chemosphere, 66: 1153-1159.

Mackay D, Shiu W, Ma K. 1997. Illustrated Handbook of Physical-Chemical Properties and Environmental Fate for Organic Chemicals (Volume V): Pesticide chemicals. Lewis Publishers: Boca Raton FL; 1-84.

Martens D, Schramm KW, Kettrup A. 1999. Standard operation procedures for the determination of chlorinated hydrocarbons in sediments, suspended solids and surface waters. In On the Presence of Polychlorinated Organic Compounds in the Liao River and the Yantse River in Eastern China. European Commission EUR-Report 18702 EN: Ispra; 21-28. 
Manirakiza P, Akinbamijo O, Covaci A, Pitonzo R, Schepens P. 2003. Assessment of organochlorine pesticides residues in African city farms: Banjul and Dakar case study. Archives Environ. Contamin. Toxicol., 44: 171-179.

Saba A, Messina F. 2003. Attitude towards organic foods and risk/benefit perception associated with pesticides. Food Quality Prefer., 14: 637-645.
Sattler C, Kachele H, Verch G. 2007. Assessing the intensity of pesticide use in agriculture. Agri, Ecosystem Environ., 119: 299-304.

WHO. 1989. DDT and its derivativesenvironmental aspects: environmental health criteria 83. International Programme on Chemical Safety (IPCS). 